OPEN ACCESS

Edited by:

Guillaume Chomicki,

Durham University, United Kingdom

Reviewed by:

Angela Poole,

Berry College, United States Shinichiro Maruyama,

Tohoku University, Japan

*Correspondence:

Tamar L. Goulet

tlgoulet@olemiss.edu

Specialty section:

This article was submitted to Coevolution,

a section of the journa

Frontiers in Ecology and Evolution

Received: 01 December 2020 Accepted: 09 March 2021 Published: 30 March 2021

Citation:

Goulet TL and Goulet D (2021) Climate Change Leads to a Reduction in Symbiotic Derived Cnidarian Biodiversity on Coral Reefs. Front. Ecol. Evol. 9:636279. doi: 10.3389/fevo.2021.636279

\section{Climate Change Leads to a Reduction in Symbiotic Derived Cnidarian Biodiversity on Coral Reefs}

\author{
Tamar L. Goulet* and Denis Goulet \\ Department of Biology, University of Mississippi, University, MS, United States
}

Symbiotic relationships enable partners to thrive and survive in habitats where they would either not be as successful, or potentially not exist, without the symbiosis. The coral reef ecosystem, and its immense biodiversity, relies on the symbioses between cnidarians (e.g., scleractinian corals, octocorals, sea anemones, jellyfish) and multiple organisms including dinoflagellate algae (family Symbiodiniaceae), bivalves, crabs, shrimps, and fishes. In this review, we discuss the ramifications of whether coral reef cnidarian symbioses are obligatory, whereby at least one of the partners must be in the symbiosis in order to survive or are facultative. Furthermore, we cover the consequences of cnidarian symbioses exhibiting partner flexibility or fidelity. Fidelity, where a symbiotic partner can only engage in symbiosis with a subset of partners, may be absolute or context dependent. Current literature demonstrates that many cnidarian symbioses are highly obligative and appear to exhibit absolute fidelity. Consequently, for many coral reef cnidarian symbioses, surviving changing environmental conditions will depend on the robustness and potential plasticity of the existing host-symbiont(s) combination. If environmental conditions detrimentally affect even one component of this symbiotic consortium, it may lead to a cascade effect and the collapse of the entire symbiosis. Symbiosis is at the heart of the coral reef ecosystem, its existence, and its high biodiversity. Climate change may cause the demise of some of the cnidarian symbioses, leading to subsequent reduction in biodiversity on coral reefs.

Keywords: symbiosis, mutualism, coral, octocoral, sea anemone, anemonefish, coral reef fish, jellyfish

\section{INTRODUCTION}

In 1878, de Bary defined symbiosis as the "living together of differently named organisms" (translated in Oulhen et al., 2016). "Living together" can lead to organisms existing in habitats where they may not survive if not for the symbiosis, increasing the biodiversity in that habitat. "Living together" can also create novel biological entities, a consortium of organisms. When symbionts are within (endosymbionts) or on (ectosymbionts) the tissue of the host, the host-symbiont(s) entity, the holobiont (Margulis, 1991), may exhibit novel physiological and ecological attributes. Although some debate the evolutionary utility of this term (Skillings, 2016), numerous holobiont characteristics differ from the properties of the organisms in isolation (reviewed in Goulet et al., 2020). Furthermore, host-symbiont genotypic combinations generate diverse holobionts that differ physiologically and ecologically from one another (Goulet et al., 2005). Therefore, different 
symbioses and holobionts can lead to increased variability within and between host species, both contributing to overall biodiversity in an ecosystem.

Symbioses are ubiquitous in terrestrial and aquatic habitats, from the tube worm-sulfur oxidizing bacteria in deep sea hydrothermal vents (Cavanaugh et al., 1981), to the fungal-blue green algal symbiosis in arctic lichens (Crittenden and Kershaw, 1978). In some habitats, symbioses are key to the existence of an entire ecosystem, as occurs on coral reefs. In this review, we focus on the symbioses between members of the phylum cnidaria (e.g., scleractinian corals, octocorals, sea anemones, jellyfish) and their symbionts. These symbioses shape biodiversity on coral reefs, but with climate change, these pivotal symbioses may falter, leading to a loss of biodiversity. The structural complexity of coral reefs may then be reduced (Rossi et al., 2019), detrimentally affecting other organisms in the ecosystem. The degree of reliance on the partners within cnidarian symbioses, and their fidelity, may potentially lead to their demise.

\section{The Symbiotic Continuum and Its Influences on Biodiversity}

de Bary's definition of symbiosis described a phenomenon, not its ramifications. Subsequently, attributes were assigned to symbioses based on benefits and costs, from mutualism (both partners benefit), commensalism (one partner benefits while the other is neither harmed nor gains a benefit), parasitism (one partner benefits while the other is harmed) (Saffo, 1993), to the recently added amensalism (one partner is harmed while the other is neither harmed nor gains a benefit) (Apprill, 2020). We adhere to the subdivisions of symbiosis (Saffo, 1993), as opposed to treating symbiosis as a synonym for mutualism (Douglas, 2010). Although the symbiotic states may appear as discrete boxes (Figure 1A), or a sliding continuum (Figure 1B; Lesser et al., 2013), neither portrayal captures the complexities of symbioses, since the former assumes that a symbiosis is constrained into one category while the latter implies that a mutualism needs to transition into a commensalism or amensalism before it may morph into a parasitism, and vice versa. Alternatively, symbiotic states may oscillate from one to another (Figure 1C) based on the context. Changing environmental conditions, which often occur in conjunction with climate change, may be an impetus for such symbiotic shifts. Conversely, if the symbiotic partner(s) rely on a certain symbiotic state, environmental changes may lead to symbiosis breakdown and even partner death (Figure 1C).

\section{The Benefits Brought About by Cnidarian Symbioses on Coral Reefs}

The core of the coral reef ecosystem is the mutualism between members of the phylum cnidaria and unicellular dinoflagellate algae (family Symbiodiniaceae). Symbiodiniaceae transfer some of their photosynthetically fixed carbohydrates to the cnidarian host (Muscatine and Porter, 1977), contributing as much as $143 \%$ of the coral's maintenance respiration (Muscatine et al., 1984). But, Symbiodiniaceae differ in their metabolic contribution to their hosts, with some Symbiodiniaceae even

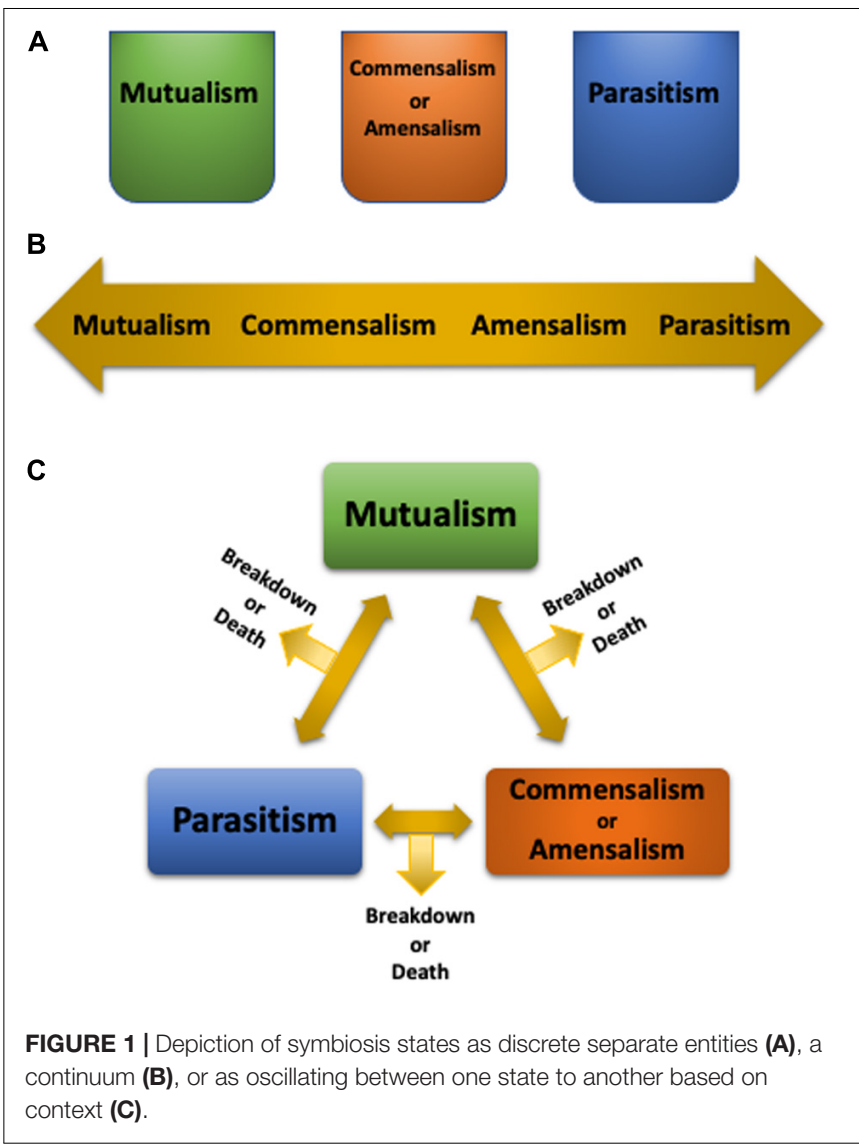

acting as parasitic at some stage in host ontogeny (Banaszak et al., 2013) or under different environmental conditions (Lesser et al., 2013), reiterating symbiotic state oscillation (Figure 1C). The cnidarian host, through their pigments, may enhance Symbiodiniaceae photosynthesis (Schlichter et al., 1994), even in light limited mesophotic depths (Schlichter et al., 1986). Scleractinian corals' calcification is increased by Symbiodiniaceae, thereby enhancing coral growth which then affects the overall coral reef structure (Goreau and Goreau, 1959; Pearse and Muscatine, 1971), influencing the organisms that rely on the reef for habitat and/or food. From the host's nitrogenous wastes, Symbiodiniaceae gain a steady nitrogen source in an oligotrophic habitat (Muscatine and D'Elia, 1978). As endosymbionts, the Symbiodiniaceae exposure to environmental parameters such as ultraviolet radiation and thermal stress is attenuated (Kawaguti, 1944; Shibata, 1969; Goulet et al., 2005).

In addition to Symbiodiniaceace, cnidarians contain bacteria and Archaea (reviewed in Knowlton and Rohwer, 2003; Bourne et al., 2016; Peixoto et al., 2017). Bacteria may provide a source of sulfur, nitrogen and carbon, and protect cnidarians via antibiotics, inhibitors, and out competing other microbes (Shashar et al., 1994; reviewed in Knowlton and Rohwer, 2003; McDevitt-Irwin et al., 2017; Peixoto et al., 2017). From cnidarian mucus, bacteria can obtain wax ester and triglycerides (Johannes, 1967; Benson and Muscatine, 1974). Cnidarians may 
also obtain benefits from Archaea aiding in nitrogen cycling, gene transfer from viruses, and fungal anti-microbial activity and contribution to the carbon and nitrogen cycles (reviewed in Knowlton and Rohwer, 2003 and Peixoto et al., 2017). On the other hand, viruses, bacteria, and fungi may harm the symbioses and are associated with cnidarian diseases (Richardson, 1998; Mera and Bourne, 2018). The data on non-Symbiodinaceae microbiome members are predominantly limited to identifying the entities involved, with a paucity of data on their role and function (Bourne et al., 2016). Furthermore, despite the tight coupling of scleractinian coral-bacteria phylogenies (Pollock et al., 2018), some argue that the relationship with bacteria should not be put in symbiotic terms (Mushegian and Ebert, 2016). Hence, although we recognize that bacteria, Archaea and other entities exist in cnidarians, given the current limited knowledge of their relationships, we do not discuss them in the subsequent sections.

Cnidarians also form symbioses with macro organisms such as bivalves (Mokady et al., 1998), crabs, shrimp (Glynn, 1980), and fish (Collingwood, 1868; Mariscal, 1970; Liberman et al., 1995; Howell et al., 2016) that continuously dwell within and between cnidarian branches/tentacles. Macro organisms can provide protection to their cnidarians; crabs and shrimp nip at the tube feet of the coral predator star fish Acanthaster planci (Glynn, 1980), and resident fishes chase away predators (Mariscal, 1970; Chase et al., 2014). Cnidarian dwelling fish remove sedimentation and debris from their hosts (Mariscal, 1970; Liberman et al., 1995). In addition, boring bivalves (Mokady et al., 1998), shrimp (Spotte, 1996), and fish (Roopin and Chadwick, 2009) provide their nitrogenous waste to the symbiosis. Coral dwelling fish's movements within their host contribute to coral oxygenation as proposed in Liberman et al. (1995) and demonstrated in Goldshmid et al. (2004). Many cnidarian dwelling macro organisms rely on their host cnidarian for their habitat and protection (Mariscal, 1970) in addition to utilizing the coral mucus, and occasionally coral tissue for nutrition.

\section{Obligate vs. Facultative Cnidarian Symbioses}

In most of the symbioses with coral reef cnidarians, at least one of the partners obligatorily engages in the symbiosis in order to survive. For example, many cnidarians obligatorily host Symbiodiniaceae, and some jellyfish even require Symbiodiniaceae infection to enter a stage in their life cycle (Ohdera et al., 2018; Djeghri et al., 2019). Conversely, Symbiodiniaceae genetic signatures were detected from open water samples (Decelle et al., 2018), and Symbiodiniaceae in feces of fish and a nudibranch that fed on anemones were viable (Muller Parker, 1984), indicating that the mutualism may not be reciprocally obligative. Perturbations can lead to a reduction in algal numbers and/or chlorophyll content per Symbiodiniaceae cell within cnidarian hosts, termed coral bleaching, which may lead to cnidarian death (Glynn, 1996). The same environmental perturbations, however, affect cnidarian symbioses differently, resulting in within (Berkelmans and van
Oppen, 2006; Goulet et al., 2008; Sampayo et al., 2008) and between (Marshall and Baird, 2000; Goulet et al., 2008) species differences in susceptibility and survival. Coral species that can offset the loss of nutrients, brought about from the reduction in Symbiodiniaceae, with heterotrophic input via predation, often withstand perturbations better than coral species that are more autotrophic (Grottoli et al., 2006).

Many fish obligatorily associate with corals (Liberman et al., 1995) or sea anemones (Collingwood, 1868, reviewed in Fautin, 1991). Conversely, not all corals or anemones, even of the same species, at the same depth and habitat, host fish (Liberman et al., 1995; Chadwick and Arvedlund, 2005) or shrimp (Spotte, 1996), demonstrating the facultative nature of the relationships for the cnidarians. Furthermore, even though mutualisms are often referred to as a partnership between two organisms, most often mutualisms occur in networks, with a nested hierarchy between the members. Cnidarians epitomize the consortium concept (reviewed in Goulet et al., 2020) and the multilevel effects. Although macro symbionts associate with the cnidarian hosts, their nitrogen excretions provide nitrogen for the Symbiodiniaceae (Spotte, 1996; Mokady et al., 1998). The complexity of the interactions in the symbioses, along with their obligative vs. facultative nature, may further compound the effects of climate changes on them.

\section{DISCUSSION}

When symbioses face changing environmental conditions, several scenarios are plausible (Kiers et al., 2010). An existing mutualistic symbiosis may either thrive, or it may shift from beneficial to antagonistic (Figure 1C). Conversely, the current symbiosis may be dissolved and a new partnership formed, or the symbiosis may breakdown (Figure 1C; Kiers et al., 2010), potentially leading to the death of one if not all of the symbiotic partners (Kiers et al., 2010, 2015). Since holobiont adaptability may occur at a faster rate than evolutionary change of the hosts, cnidarian symbioses may survive climate change (Apprill, 2020). On the other hand, if the vast majority of cnidarian symbioses on coral reefs are obligatory with high fidelity, the range of potential scenarios for cnidarian symbioses faced with climate change may be limited, potentially leading to an overall reduction in cnidarian symbioses and biodiversity.

\section{The Consequences of Obligate vs. Facultative Cnidarian Symbioses on Biodiversity on Coral Reefs Under Climate Change}

A symbiosis can be obligate and resilient at the same time. If the symbiosis is physiologically plastic and robust, it will survive a perturbation. Alternatively, a stressor can adversely affect a symbiosis. The more reliant a partner is on the symbiosis, the more vulnerable it is if the symbiosis falters (Chomicki et al., 2019). When a coral bleaches, residual Symbiodiniaceae remain (Hayes and Bush, 1990), and if they repopulate the host, 
the symbiosis survives. Conversely, if a cnidarian host cannot repopulate or switch its Symbiodiniaceae, coral bleaching may lead to coral death.

If the obligate cnidarian-algal symbiosis is detrimentally affected by abiotic or biotic factors, other obligate symbionts will also be adversely affected. For example, the metabolic rate of juvenile clownfish Amphiprion chrysopterus inhabiting bleached Heteractis magnifica sea anemones was higher than in anemonefish inhabiting non-bleached anemones (Norin et al., 2018). Egg production in female $A$. polymnus in bleached Stichodactyla hadonni and $H$. crispa anemones was reduced by $38 \%$ compared to egg production in nonbleached anemones (Saenz-Agudelo et al., 2011). The effects on individual anemones and their symbionts in turn affects the populations of both. On a reef in the Gulf of Eilat (Aqaba) Red Sea, from 1997 to 2015 the number of the sea anemones, $H$. crispa and Entacmaea quadricolor, declined by 86\% (Howell et al., 2016). Concurrently, a 74\% reduction in the anemonefish $A$. bicinctus population occurred. In the original censuses, about $50 \%$ of sea anemones were inhabited by $A$. bicinctus. By 2015, all 25 sea anemones in the population were occupied by anemonefish, potentially limiting subsequent anemonefish recruitment (Howell et al., 2016). Hence, if the sea anemone population continues to decline on this reef, the reef biodiversity will be lowered with the loss of both the sea anemones and their resident anemonefish. Such a consequence occurred in the Keppel Islands, Australia, where a decade after a fishing moratorium not only did the sea anemone E. quadricolor and the anemonefish A. melanopus populations not bounce back to historic densities, but the anemone $H$. crispa and anemonefish $A$. clarkii were not seen in the surveys, demonstrating the dramatic decline in that symbiosis (Frisch et al., 2019).

Likewise, Trapezia cymodoce, a crab that obligatorily associates with scleractinian corals, was detrimentally affected when its host Pocillopora damicornis bleached (Stella et al., 2011). Trapezia egg clutch sizes were lower in bleached than in healthy corals (Stella et al., 2011). In bleached corals, either both members of the Trapezia breeding pair were lost, or only one Trapezia remained. A laboratory experiment demonstrated that Trapezia abandoned a bleached coral in search of a healthy one, with larger Trapezia usurping the resident smaller Trapezia (Stella et al., 2011). Hence, the bleaching in P. damicornis led to a reduction of the resident Trapezia fecundity and population and, through emigration, also affected Trapezia in healthy corals (Stella et al., 2011).

\section{The Consequences of Cnidarian Symbiotic Partner(s) Fidelity vs. Flexibility on Coral Reef Biodiversity Under Climate Change}

In both obligatory and facultative cnidarian symbioses, the symbionts may exhibit high fidelity, whereby a cnidarian species associates with a subset of symbionts, and vice versa. Alternatively, a host and/or symbiont may be flexible, forming symbioses indiscriminately. On coral reefs, many cnidarian symbioses demonstrate fidelity. Even if multiple entities can enter the host cnidarian, such as in initial Symbiodiniaceae or bacterial acquisition, winnowing occurs and the adult cnidarians exhibit symbiont affinity (Coffroth et al., 2001; Abrego et al., 2009; Epstein et al., 2019). Similarly, when a coral species hosts two or more Symbiodiniaceae genera, specific Symbiodiniaceae species within these genera associate with that given species (Goulet, 2006, 2007; Hume et al., 2020). Bacteria exhibit fidelity to cnidarian host species (Ainsworth et al., 2015; Shirur et al., 2016; van de Water et al., 2017, 2018; Huggett and Apprill, 2019; McCauley et al., 2020). Likewise, resident crabs, shrimp and fish associate with specific cnidarian species (Fishelson et al., 1974).

\section{Is Fidelity Absolute or Context Dependent?}

If fidelity occurs in a symbiosis, even for one of the partners, this may limit the potential range of responses of the holobiont to changing environmental conditions. Faced with climate change, with high fidelity, an existing host-symbiont(s) genotypic combination may be limited to the two outcomes of either surviving or dying. Alternatively, what appears as fidelity may be a context dependent consequence, i.e., under certain environmental conditions, a specific host-symbiont pairing may form since that is the best combination for those conditions. If the conditions change, then that host-symbiont combination may not be optimal, which may lead to a different hostsymbiont symbiosis forming either during the establishment of the symbiosis (Baird et al., 2007) or in an existing symbiosis (Baker, 2003).

To tease apart if the fidelity exhibited in a certain symbiosis is absolute or context-dependent, one can pursue several investigative directions. Comparing cnidarian gene and metabolite expression profiles with homologous vs. heterologous symbionts may shed light on the cnidarian reaction to heterologous symbionts and if novel host-symbiont genotypic combinations are feasible (Matthews et al., 2017). Furthermore, if fidelity appears to exist because of the symbiosis' stability under certain environmental conditions, then if environmental parameters are pushed beyond a potential threshold, a different symbiosis partnership may form. Thus far, changing environmental conditions such as sea water temperatures, ultraviolet radiation, nutrient enrichment, reduction in $\mathrm{pH}$ and transplantation to different habitats on the same and different reefs have not resulted in the establishment of novel, persistent symbioses (reviewed in Goulet, 2006). In scleractinian corals, novel Symbiodiniaceae were detected following environmental change, but these Symbiodiniaceae were transient (Thornhill et al., 2006; Sampayo et al., 2008; Lee et al., 2016). If the perturbation did not lead to the demise of the symbiosis, the specific cnidarian-Symbiodiniaceae combination re-established itself. Nevertheless, one could argue that the symbioses have not been pushed to the point that would lead to flexibility (Baird et al., 2007). Thus far, experimental attempts at creating hardier artificial holobionts in the sea anemone Exaiptasia, by inoculating Exaiptasia with a 
more thermally tolerant Symbiodiniaceae, have not succeeded, with Exaiptasia displaying selectivity to its specific symbiont (Gabay et al., 2019; Herrera et al., 2020), countering the idea that these symbioses can change.

\section{How Do the Effects of Climate Change on a Member of a Symbiotic Consortium Impact the Consortium as a Whole? Are There Cascade Effects?}

Since cnidarian symbioses can contain a multitude of symbiotic interactions, changes in environmental conditions may affect only one, some, or all of the partners, and the degree and the directionality of the effect may vary (Goulet, 2015). Furthermore, even if the environmental change directly affects only one of the partners, since the symbiotic partners are interconnected, the entire symbiotic consortium may be affected. For example, elevated seawater temperatures can detrimentally affect Symbiodiniaceae photosynthesis which may in turn detrimentally affect the cnidarian host and hence the entire symbiosis (Warner et al., 1999). Even if the Symbiodiniaceae are not directly influenced by a stressor, the cnidarian host may be affected (Baird et al., 2009). Since the Symbiodiniaceae reside within their cnidarian host, death of the host will lead to the demise of the entire symbiosis. Conversely, the interplay of the potential negative, neutral, and positive effects may, in essence, cancel each other out, resulting in the symbiotic cnidarian consortium surviving and potentially thriving under the new environmental conditions. In order to potentially predict the effects of a stressor on a cnidarian species, and hence coral reef biodiversity, one needs to assess the effects of the stressor on the consortium.

Selective symbiosis survival may lead to a reduction in biodiversity both within and between species. For example, on the Great Barrier Reef, the scleractinian coral Stylophora pistillata hosts multiple Symbiodiniaceae types within the genus Cladocopium. In a thermal event, S. pistillata colonies hosting Cladocopium C79 and C35/a died at a higher proportion than those hosting C78 and C8/a. As a result, although S. pistillata still existed on the reef, the symbiosis diversity within $S$. pistillata was reduced (Sampayo et al., 2008). Likewise, in the coral Montipora digitata genotypic variability in both the host coral and Symbiodiniaceae led to differential stress susceptibility between coral holobionts (Kavousi et al., 2020).

\section{REFERENCES}

Abrego, D., Van Oppen, M. J. H., and Willis, B. L. (2009). Highly infectious symbiont dominates initial uptake in coral juveniles. Mol. Ecol. 18, 3518-3531. doi: 10.1111/j.1365-294x.2009.04275.x

Ainsworth, T. D., Krause, L., Bridge, T., Torda, G., Raina, J.-B., Zakrzewski, M., et al. (2015). The coral core microbiome identifies rare bacterial taxa as ubiquitous endosymbionts. ISME J. 9, 2261-2274. doi: 10.1038/ismej.2015.39

Apprill, A. (2020). The role of symbioses in the adaptation and stress responses of marine organisms. Ann. Rev. Mar. Sci. 12, 291-314. doi: 10.1146/annurevmarine-010419-010641

\section{CONCLUSION}

Living together in symbioses may enable organisms to inhabit environments where they may not exist in isolation. Obligate and/or high fidelity in symbioses may lead to increased biodiversity in an ecosystem because of the many intra and interspecific host-symbiont genotypic combinations. Such is the case on coral reefs where cnidarian symbioses drive the ecosystem. When environmental conditions change, mutualism may transition to parasitism, the symbiosis may be abandoned, the existing host-symbiont(s) genotypic combination may withstand the perturbation, or the entire symbiosis will collapse. The obligate and fidelity of many cnidarian symbioses will make symbiotic transitions probably unlikely. The strength of a specific obligate symbiosis may be its downfall, leading to a reduction in intra and interspecific biodiversity. Understanding the nature of cnidarian symbioses (obligative to facultative, fidelity vs. flexibility), the symbiotic consortium, and the effects of the environment on these symbioses, will advance our knowledge of the current and future biodiversity of cnidarian symbioses on coral reefs.

\section{AUTHOR CONTRIBUTIONS}

TLG and DG contributed to the conception of the review, manuscript revision, and read and approved the submitted version. TLG wrote the manuscript. Both authors contributed to the article and approved the submitted version.

\section{FUNDING}

Funding was provided by the National Science Foundation (NSF, DEB, Grant No. 1839775) to TLG. Any opinions, findings, and conclusions or recommendations expressed in this material are those of the authors and do not necessarily reflect the views of the National Science Foundation.

\section{ACKNOWLEDGMENTS}

We thank Savannah Draud, Akacia Halliday, and Jordan Heiman for their comments. This is publication number 023 of the Center for Biodiversity and Conservation Research at The University of Mississippi.

Baird, A. H., Bhagooli, R., Ralph, P. J., and Takahashi, S. (2009). Coral bleaching: the role of the host. Trends Ecol. Evol. 24, 16-20. doi: 10.1016/j.tree.2008.09.005

Baird, A. H., Cumbo, V. R., Leggat, W., and Rodriguez-Lanetty, M. (2007). Fidelity and flexibility in coral symbioses. Mar. Ecol. Prog. Ser. 347, 307-309. doi: 10.3354/meps07220

Baker, A. C. (2003). Flexibility and specificity in coral-algal symbiosis: diversity, ecology, and biogeography of Symbiodinium. Annu. Rev. Ecol. Evol. Syst. 34, 661-689. doi: 10.1146/annurev.ecolsys.34.011802. 132417

Banaszak, A. T., García Ramos, M., and Goulet, T. L. (2013). The symbiosis between the gastropod Strombus gigas and the dinoflagellate Symbiodinium: an 
ontogenic journey from mutualism to parasitism. J. Exp. Mar. Biol. Ecol. 449, 358-365. doi: 10.1016/j.jembe.2013.10.027

Benson, A. A., and Muscatine, 1. (1974). Wax in coral mucus: energy transfer from corals to reef fishes. Limnol. Oceanogr. 19, 810-814. doi: 10.4319/lo.1974.19.5. 0810

Berkelmans, R., and van Oppen, M. J. H. (2006). The role of zooxanthellae in the thermal tolerance of corals: a 'nugget of hope' for coral reefs in an era of climate change. Proc. R. Soc. B Biol. Sci. 273, 2305-2312. doi: 10.1098/rspb.2006. 3567

Bourne, D. G., Morrow, K. M., and Webster, N. S. (2016). Insights into the coral microbiome: underpinning the health and resilience of reef ecosystems. Annu. Rev. Microbiol. 70, 317-340. doi: 10.1146/annurev-micro-102215-095440

Cavanaugh, C. M., Gardiner, S. L., Jones, M. L., Jannasch, H. W., and Waterbury, J. B. (1981). Prokaryotic cells in the hydrothermal vent tube worm Riftia pachyptila Jones: possible chemoautotrophic symbionts. Science 213, 340-342. doi: 10.1126/science.213.4505.340

Chadwick, N. E., and Arvedlund, M. (2005). Abundance of giant sea anemones and patterns of association with anemonefishin the northern Red Sea. J. Mar. Biol. Assoc. U. K. 85, 1287-1292. doi: 10.1017/s0025315405012440

Chase, T., Pratchett, M., Walker, S., and Hoogenboom, M. (2014). Small-scale environmental variation influences whether coral-dwelling fish promote or impede coral growth. Oecologia 176, 1009-1022. doi: 10.1007/s00442-0143065-9

Chomicki, G., Weber, M., Antonelli, A., Bascompte, J., and Kiers, E. T. (2019). The impact of mutualisms on species richness. Trends Ecol. Evol. 34, 698-711. doi: $10.1016 /$ j.tree.2019.03.003

Coffroth, M. A., Santos, S. R., and Goulet, T. L. (2001). Early ontogenetic expression of specificity in a cnidarian-algal symbiosis. Mar. Ecol. Prog. Ser. 222, 85-96. doi: $10.3354 /$ meps 222085

Collingwood, C. (1868). IV.-Note on the existence of gigantic sea-anemones in the China Sea, containing within them quasi-parasitic fish. Ann. Mag. Nat. Hist. 1, 31-33. doi: 10.1080/00222936808695633

Crittenden, P., and Kershaw, K. (1978). Discovering the role of lichens in the nitrogen cycle in boreal-arctic ecosystems. Bryologist 81, 258-267. doi: 10.2307/ 3242187

Decelle, J., Carradec, Q., Pochon, X., Henry, N., Romac, S., Mahé, F., et al. (2018). Worldwide occurrence and activity of the reef-building coral symbiont Symbiodinium in the open Ocean. Current Biology 28, 3625-3633.e3. doi: 10. 1016/j.cub.2018.09.024

Djeghri, N., Pondaven, P., Stibor, H., and Dawson, M. N. (2019). Review of the diversity, traits, and ecology of zooxanthellate jellyfishes. Mar. Biol. 166:147. doi: 10.1007/s00227-019-3581-6

Douglas, A. E. (2010). The Symbiotic Habit. Princeton, NJ: Princeton University Press, 202.

Epstein, H. E., Torda, G., Munday, P. L., and van Oppen, M. J. H. (2019). Parental and early life stage environments drive establishment of bacterial and dinoflagellate communities in a common coral. ISME J. 13, 1635-1638. doi: 10.1038/s41396-019-0358-3

Fautin, D. G. (1991). The anemonefish symbiosis: what is known and what is not. Symbiosis 10, 23-46.

Fishelson, L., Popper, D., and Avidor, A. (1974). Biosociology and ecology of pomacentrid fishes around the Sinai Peninsula (northern Red Sea). J. Fish Biol. 6, 119-133. doi: 10.1111/j.1095-8649.1974.tb04532.x

Frisch, A. J., Hobbs, J.-P. A., Hansen, S. T., Williamson, D. H., Bonin, M. C., Jones, G. P., et al. (2019). Recovery potential of mutualistic anemone and anemonefish populations. Fish. Res. 218, 1-9. doi: 10.1016/j.fishres.2019. 04.018

Gabay, Y., Parkinson, J. E., Wilkinson, S. P., Weis, V. M., and Davy, S. K. (2019). Inter-partner specificity limits the acquisition of thermotolerant symbionts in a model cnidarian-dinoflagellate symbiosis. ISME J. 13, 2489-2499. doi: 10.1038/ s41396-019-0429-5

Glynn, P. W. (1980). Defense by symbiotic crustacea of host corals elicited by chemical cues from predator. Oecologia 47, 287-290. doi: 10.1007/bf00398518

Glynn, P. W. (1996). Coral reef bleaching: facts, hypotheses and implications. Glob. Chang. Biol. 2, 495-509. doi: 10.1111/j.1365-2486.1996.tb00063.x

Goldshmid, R., Holzman, R., Weihs, D., and Genin, A. (2004). Aeration of corals by sleep swimming fish. Limnol. Oceanogr. 49, 1832-1839. doi: 10.4319/lo.2004. 49.5.1832
Goreau, T. F., and Goreau, N. I. (1959). The physiology of skeleton formation in corals. II. Calcium depostion by hermatypic corals under various conditions in the reef. Biol. Bull. 117, 239-250. doi: 10.2307/1538903

Goulet, T. L. (2006). Most corals may not change their symbionts. Mar. Ecol. Prog. Ser. 321, 1-7. doi: 10.3354/meps321001

Goulet, T. L. (2007). Most scleractinian corals and octocorals host a single symbiotic zooxanthella clade. Mar. Ecol. Prog. Ser. 335, 243-248. doi: 10.3354/ meps335243

Goulet, T. L. (2015). “The importance of the combined host-symbiont (holobiont) perspective in studies of cnidarian-Symbiodinium mutualisms. Box 10.3 in Chapter 10, Context-dependent outcomes of mutualistic interactions by Hoeksema, J.D. and Bruna, E.M," in Mutualism, ed. J. L. Bronstein (New York, NY: Oxford University Press), 194. doi: 10.1093/acprof:oso/9780199675654. 003.0010

Goulet, T. L., Cook, C. B., and Goulet, D. (2005). Effect of short-term exposure to elevated temperatures and light levels on photosynthesis of different hostsymbiont combinations in the Aiptasia pallida / Symbiodinium symbiosis. Limnol. Oceanogr. 50, 1490-1498. doi: 10.4319/lo.2005.50.5.1490

Goulet, T. L., Erill, I., Ascunce, M. S., Finley, S. J., and Javan, G. T. (2020). Conceptualization of the holobiont paradigm as it pertains to corals. Front. Physiol. 11:566968. doi: 10.3389/fphys.2020.566968

Goulet, T. L., LaJeunesse, T. C., and Fabricius, K. E. (2008). Symbiont specificity and bleaching susceptibility among soft corals in the 1998 Great Barrier Reef mass coral bleaching event. Mar. Biol. 154, 795-804. doi: 10.1007/s00227-0080972-5

Grottoli, A. G., Rodrigues, L. J., and Palardy, J. E. (2006). Heterotrophic plasticity and resilience in bleached corals. Nature 440, 1186-1189. doi: 10.1038/ nature 04565

Hayes, R. L., and Bush, P. G. (1990). Microscopic observations of recovery in the reef-building scleractinian coral, Montastrea annularius, after bleaching on a Cayman reef. Coral Reefs 8, 203-209. doi: 10.1007/bf00265012

Herrera, M., Klein, S. G., Schmidt-Roach, S., Campana, S., Cziesielski, M. J., Chen, J. E., et al. (2020). Unfamiliar partnerships limit cnidarian holobiont acclimation to warming. Globa. Chang. Biol. 26, 5539-5553. doi: 10.1111/gcb. 15263

Howell, J., Goulet, T. L., and Goulet, D. (2016). Anemonefish musical chairs and the plight of the two-band anemonefish, Amphiprion bicinctus. Environ. Biol. Fish. 99, 873-886. doi: 10.1007/s10641-016-0530-9

Huggett, M. J., and Apprill, A. (2019). Coral microbiome database: integration of sequences reveals high diversity and relatedness of coral-associated microbes. Environ. Microbiol. Rep. 11, 372-385. doi: 10.1111/1758-2229.12686

Hume, B. C. C., Mejia-Restrepo, A., Voolstra, C. R., and Berumen, M. L. (2020). Fine-scale delineation of Symbiodiniaceae genotypes on a previously bleached central Red Sea reef system demonstrates a prevalence of coral host-specific associations. Coral Reefs 39, 583-601. doi: 10.1007/s00338-020-01917-7

Johannes, R. E. (1967). Ecology of organic aggregates in the vicinity of a coral reef limnology and oceanography. Limnol. Oceanogr. 12, 189-195. doi: 10.4319/lo. 1967.12.2.0189

Kavousi, J., Denis, V., Sharp, V., Reimer, J. D., Nakamura, T., and Parkinson, J. E. (2020). Unique combinations of coral host and algal symbiont genotypes reflect intraspecific variation in heat stress responses among colonies of the reefbuilding coral, Montipora digitata. Mar. Biol. 167:23. doi: 10.1007/s00227-0193632-z

Kawaguti, S. (1944). On the physiology of corals. VI Study on the pigments. Contr. Palao Trop. Biol. Stn. 2, 616-673.

Kiers, E. T., Ives, A. R., and Kawakit, A. (2015). "Global change and mutualisms," in Mutualism, ed. J. L. Bronstein (New York, NY: Oxford University Press), 241-267. doi: 10.1093/acprof:oso/9780199675654.003.0013

Kiers, T. E., Palmer, T. M., Ives, A. R., Bruno, J. F., and Bronstein, J. L. (2010). Mutualisms in a changing world: an evolutionary perspective. Ecol. Lett. 13, 1459-1474. doi: 10.1111/j.1461-0248.2010.01538.x

Knowlton, N., and Rohwer, F. (2003). Multispecies microbial mutualisms on coral reefs: the host as a habitat. Am. Nat. 162(Suppl. 4), S51-S62. doi: 10.1086/ 378684

Lee, M. J., Jeong, H. J., Jang, S. H., Lee, S. Y., Kang, N. S., Lee, K. H., et al. (2016). Most low-abundance "background" Symbiodinium spp. are transitory and have minimal functional significance for symbiotic corals. Microb. Ecol. 71, 771-783. doi: $10.1007 / \mathrm{s} 00248-015-0724-2$ 
Lesser, M. P., Stat, M., and Gates, R. D. (2013). The endosymbiotic dinoflagellates (Symbiodinium sp.) of corals are parasites and mutualists. Coral Reefs 32, 603-611. doi: 10.1007/s00338-013-1051-Z

Liberman, T., Genin, A., and Loya, Y. (1995). Effects on growth and reproduction of the coral Stylophora pistillata by the mutualistic damselfish Dascyllus marginatus. Mar. Biol. 121, 741-746. doi: 10.1007/bf00349310

Margulis, L. (1991). "Symbiogenesis and symbionticism," in Symbiosis as a Source of Evolutionary Innovation: Speciation and Morphogenesis, eds L. Margulis and R. Fester (Cambridge MA: MIT Press), 1-14.

Mariscal, R. N. (1970). The nature of the symbiosis between Indo-Pacific anemone fishes and sea anemones. Mar. Biol. 6, 58-65. doi: 10.1007/bf00352608

Marshall, P. A., and Baird, A. H. (2000). Bleaching of corals on the Great Barrier Reef: differential susceptibilities among taxa. Coral Reefs 19, 155-163. doi: $10.1007 / \mathrm{s} 003380000086$

Matthews, J. L., Crowder, C. M., Oakley, C. A., Lutz, A., Roessner, U., Meyer, E., et al. (2017). Optimal nutrient exchange and immune responses operate in partner specificity in the cnidarian-dinoflagellate symbiosis. Proc. Natl. Acad. Sci. U.S.A. 114, 13194-13199. doi: 10.1073/pnas.1710733114

McCauley, M., Jackson, C. R., and Goulet, T. L. (2020). Microbiomes of Caribbean octocorals vary over time but are resistant to environmental change. Front. Microbiol. 11:1272. doi: 10.3389/fmicb.2020.01272

McDevitt-Irwin, J. M., Baum, J. K., Garren, M., and Vega Thurber, R. L. (2017). Responses of coral-associated bacterial communities to local and global stressors. Front. Mar. Sci. 4:262. doi: 10.3389/fmars.2017.00262

Mera, H., and Bourne, D. G. (2018). Disentangling causation: complex roles of coral associated microorganisms in disease. Environ. Microbiol. 20, 431-449. doi: 10.1111/1462-2920.13958

Mokady, O., Loya, Y., and Lazar, B. (1998). Ammonium contribution from boring bivalves to their coral host - a mutualistic symbiosis? Mar. Ecol. Prog. Ser. 169, 295-301. doi: 10.3354/meps169295

Muller Parker, G. (1984). Dispersal of zooxanthellae on coral reefs by predators on cnidarians. Biol. Bull. (Woods Hole) 167, 159-167. doi: 10.2307/1541344

Muscatine, L., and D'Elia, C. F. (1978). The uptake, retention, and release of ammonium by reef corals. Limnol. Oceanogr. 23, 725-734. doi: 10.4319/lo.1978. 23.4.0725

Muscatine, L., Falkowski, P. G., Porter, J. W., and Dubinsky, Z. (1984). Fate of photosynthetic fixed carbon in light- and shade-adapted colonies of the symbiotic coral Stylophora pistillata. Proc. R. Soc. Lond. B 222, 181-202. doi: 10.1098/rspb.1984.0058

Muscatine, L., and Porter, J. (1977). Reef corals: mutualistic symbioses adapted to nutrient-poor environments. Bioscience 27, 454-460. doi: 10.2307/1297526

Mushegian, A. A., and Ebert, D. (2016). Rethinking "mutualism" in diverse host symbiont communities. BioEssays 38, 100-108. doi: 10.1002/bies.20150 0074

Norin, T., Mills, S. C., Crespel, A., Cortese, D., Killen, S. S., and Beldade, R. (2018). Anemone bleaching increases the metabolic demands of symbiont anemonefish. Proc. R. Soc. B Biol. Sci. 285:20180282. doi: 10.1098/rspb.2018. 0282

Ohdera, A. H., Abrams, M. J., Ames, C. L., Baker, D. M., Suescún-Bolívar, L. P., Collins, A. G., et al. (2018). Upside-down but headed in the right direction: review of the highly versatile Cassiopea xamachana system. Front. Ecol. Evol. 6:35. doi: $10.3389 /$ fevo.2018.00035

Oulhen, N., Schulz, B. J., and Carrier, T. J. (2016). English translation of Heinrich Anton de Bary's 1878 speech, 'Die Erscheinung der Symbiose' ('De la symbiose'). Symbiosis 69, 131-139. doi: 10.1007/s13199-016-0409-8

Pearse, V. B., and Muscatine, L. (1971). Role of symbiotic algae (Zooxanthellae) in coral calcification. Biol. Bull. 141, 350-363. doi: 10.2307/1540123

Peixoto, R. S., Rosado, P. M., Leite, D.C.d.A., Rosado, A. S., and Bourne, D. G. (2017). Beneficial microorganisms for corals (BMC): proposed mechanisms for coral health and resilience. Front. Microbiol. 8:341. doi: 10.3389/fmicb.2017. 00341

Pollock, F. J., McMinds, R., Smith, S., Bourne, D. G., Willis, B. L., Medina, M., et al. (2018). Coral-associated bacteria demonstrate phylosymbiosis and cophylogeny. Nat. Commun. 9, 1-13. doi: 10.1038/s41467-018-07275-x

Richardson, L. L. (1998). Coral diseases: what is really known? Trends Ecol. Evol. 13, 438-443. doi: 10.1016/s0169-5347(98)01460-8
Roopin, M., and Chadwick, N. E. (2009). Benefits to host sea anemones from ammonia contributions of resident anemonefish. J. Exp. Mar. Biol. Ecol. 370, 27-34. doi: 10.1016/j.jembe.2008.11.006

Rossi, S., Isla, E., Bosch-Belmar, M., Galli, G., Gori, A., Gristina, M., et al. (2019). Changes of energy fluxes in marine animal forests of the anthropocene: factors shaping the future seascape. ICES J. Mar. Sci. 76, 2008-2019. doi: 10.1093/ icesjms/fsz147

Saenz-Agudelo, P., Jones, G. P., Thorrold, S. R., and Planes, S. (2011). Detrimental effects of host anemone bleaching on anemonefish populations. Coral Reefs 30, 497-506. doi: 10.1007/s00338-010-0716-0

Saffo, M. B. (1993). Coming to terms with a field: words and concepts in symbiosis. Symbiosis 14, 17-31.

Sampayo, E. M., Ridgway, T., Bongaerts, P., and Hoegh-Guldberg, O. (2008). Bleaching susceptibility and mortality of corals are determined by fine-scale differences in symbiont type. Proc. Natl. Acad. Sci. U.S.A. 105, 10444-10449. doi: 10.1073/pnas.0708049105

Schlichter, D., Fricke, H. W., and Weber, W. (1986). Light harvesting by wavelength transformation in a symbiotic coral of the Red Sea twilight zone. Mar. Biol. 91, 403-407. doi: 10.1007/bf00428634

Schlichter, D., Meier, U., and Fricke, H. (1994). Improvement of photosynthesis in zooxanthellate corals by autofluorescent chromatophores. Oecologia 99, 124-131. doi: 10.1007/bf00317092

Shashar, N., Cohen, Y., Loya, Y., and Sar, N. (1994). Nitrogen fixation (acetylene reduction) in stony corals: evidence for coral-bacteria interactions. Mar. Ecol. Prog. Ser. 111, 259-264. doi: 10.3354/meps111259

Shibata, K. (1969). Pigments and a UV-absorbing substance in corals and a blue-green alga living in the Great Barrier Reef. Plant Cell Physiol. 10, 325-335. doi: 10.1093/oxfordjournals.pcp.a074411

Shirur, K. P., Jackson, C. R., and Goulet, T. L. (2016). Lesion recovery and the bacterial microbiome in two Caribbean gorgonian corals. Mar. Biol. 163:238. doi: 10.1007/s00227-016-3008-6

Skillings, D. (2016). Holobionts and the ecology of organisms: multi-species communities or integrated individuals? Biol. Philos. 31, 875-892. doi: 10.1007/ s10539-016-9544-0

Spotte, S. (1996). Supply of regenerated nitrogen to sea anemones by their symbiotic shrimp. J. Exp. Mar. Biol. Ecol. 198, 27-36. doi: 10.1016/00220981(95)00169-7

Stella, J. S., Munday, P. L., and Jones, G. P. (2011). Effects of coral bleaching on the obligate coral-dwelling crab Trapezia cymodoce. Coral Reefs 30, 719-727. doi: 10.1007/s00338-011-0748-0

Thornhill, D. J., LaJeunesse, T. C., Kemp, D., Fitt, W. K., and Schmidt, G. W. (2006). Multi-year, seasonal genotypic surveys of coral-algal symbioses reveal prevalent stability or post-bleaching reversion. Mar. Biol. 148, 711-722. doi: 10.1007/s00227-005-0114-2

van de Water, J. A. J. M., Allemand, D., and Ferrier-Pagès, C. (2018). Host-microbe interactions in octocoral holobionts - recent advances and perspectives. Microbiome 6:64. doi: 10.1186/s40168-018-0431-6

van de Water, J. A. J. M., Melkonian, R., Voolstra, C. R., Junca, H., Beraud, E., Allemand, D., et al. (2017). Comparative assessment of Mediterranean gorgonian-associated microbial communities reveals conserved core and locally variant bacteria. Microb. Ecol. 73, 466-478. doi: 10.1007/s00248-0160858-x

Warner, M. E., Fitt, W. K., and Schmidt, G. W. (1999). Damage to photosystem II in symbiotic dinoflagellates: a determinant of coral bleaching. Proc. Natl. Acad. Sci. U.S.A. 96, 8007-8012. doi: 10.1073/pnas.96.14.8007

Conflict of Interest: The authors declare that the research was conducted in the absence of any commercial or financial relationships that could be construed as a potential conflict of interest.

Copyright (c) 2021 Goulet and Goulet. This is an open-access article distributed under the terms of the Creative Commons Attribution License (CC BY). The use, distribution or reproduction in other forums is permitted, provided the original author(s) and the copyright owner(s) are credited and that the original publication in this journal is cited, in accordance with accepted academic practice. No use, distribution or reproduction is permitted which does not comply with these terms. 